\title{
Diagnostic statistics of daily rainfall variability in an evolving climate
}

\author{
D. Panagoulia ${ }^{1}$, A. Bárdossy ${ }^{2}$, and G. Lourmas ${ }^{1}$ \\ ${ }^{1}$ National Technical University of Athens, School of Civil Engineering, Department of Water Resources \& Environmental \\ Engineering, 5 Heroon Polytechniou, 15780 Athens, Greece \\ ${ }^{2}$ Institute of Hydraulic Engineering, University of Stuttgart, Pfaffenwaldring 61, 70550, Stuttgart, Germany
}

Received: 7 October 2005 - Revised: 9 December 2005 - Accepted: 20 December 2005 - Published: 20 June 2006

\begin{abstract}
To investigate the character of daily rainfall variability under present and future climate described via global warming a suite of diagnostic statistics was used. The rainfall was modeled as a stochastic process coupled with atmospheric circulation. In this study we used an automated objective classification of daily patterns based on optimized fuzzy rules. This kind of classification method provided circulation patterns suitable for downscaling of General Circulation Model (GCM)-generated precipitation. The precipitation diagnostics included first and second order moments, wet and dry-day renewal process probabilities and spell lengths as well as low-frequency variability via the standard deviation of monthly totals. These descriptors were applied to nine elevation zones and entire area of the Mesochora mountainous catchment in Central Greece for observed, $1 \times \mathrm{CO}_{2}$ and $2 \times \mathrm{CO}_{2}$ downscaled precipitation. The statistics' comparison revealed significant differences in the most of the daily diagnostics (e.g. mean wet-day amount, 95th percentile of wet-day amount, dry to wet probability), spell statistics (e.g. mean wet/dry spell length), and lowfrequency diagnostic (standard deviation of monthly precipitation total) between warm $\left(2 \times \mathrm{CO}_{2}\right)$ and observed scenario in a progressive rate from lower to upper zone. The differences were very greater for the catchment area. In the light of these results, an increase in rainfall occurrence with diminished rainfall amount and a sequence of less consecutive dry days could describe the behaviour of a possible future climate on the examined catchment.
\end{abstract}

\section{Introduction}

The continued rise in concentrations of "greenhouse" gases in the atmosphere plus remote forcings associated with sea surface temperature anomalies have already created an evolving climate of the Earth (BAHC Core Project Office, 1993;

Correspondence to: D. Panagoulia

(dpanag@hydro.civil.ntua.gr)
Leroux, 1998). The general circulation models (GCMs) forced by carbon dioxide $\left(\mathrm{CO}_{2}\right)$ and other trace gases may provide predictions of climate and hydrologic cycle for any level of these gases.

However, the present generation of GCMs and higher resolution limited area models (LAMs) of the climate system are restricted in usefulness due to their coarse spatial and temporal resolution especially for variables pertaining to hydrologic cycle. In this respect, the emergence of statistical "downscaling" methods can satisfy the need for interpolation of regional-scale atmospheric predictor variables (e.g. area averages precipitation, temperature) to point-scale meteorological series (Wilby et al., 1998). Fundamental to this approach is the establishment of a stable empirical relationship between atmospheric processes occurring at disparate temporal and/or spatial scale. In the recent past, many such relationships have been developed. Mesoscale weather patterns have been used to model a variety of meteorological variables such as precipitation occurrence (Hughes and Guttorp, 1994), space-time daily rainfall patterns (Bárdossy and Plate, 1992), extreme precipitation events and drought conditions (Hay et al., 1991), and sea level anomalies (Maochang et al., 1995; Heyen et al., 1996).

The theory, practice and limitations of downscaling for present and possible future climates (global warming) are extensively described in the literature (e.g. Giorgi and Mearns, 1991; Leavesley, 1994; Wilby and Wigley, 1997; Wilby et al., 1999). The aim of this paper is more specific, namely, to compare the performance in downscaled daily rainfall variability between "observed" and "present day" (1961-2000) simulations for $1 \times \mathrm{CO}_{2}$ as a means of verifying the latter and then, "present day" and "perturbed" (2061-2100) simulations for $2 \times \mathrm{CO}_{2}$ in order to assess the possible changes due to $\mathrm{CO}_{2}$ doubling. The rainfall was modeled as a stochastic process coupled with atmospheric circulation. The automated objective classification method of daily patterns based on optimized fuzzy rules (Bárdossy et al., 2002) was undertaken. This type of classification defines circulation patterns (CPs) that can explain the variability of precipitation 
in a locally specific functional form ensuring so the dependence between large-scale atmospheric circulation and precipitation which is necessary for precipitation downscaling. The use of fuzzy rules accepts overlapping boundaries in atmospheric pressure patterns (e.g. high pressure, low pressure, etc.) providing so the capability of capturing the nonlinearity of climatic system.

For the performance of rainfall variability a suite of diagnostic statistics were used including first order and second order moments, wet and dry-day renewal process probabilities and spell lengths, and low-frequency variability, via the standard deviation of monthly totals. These descriptors were applied to nine elevation zones and entire area of the Mesochora mountainous catchment in Central Greece for downscaled daily precipitation series of observed, and ECHAM4 GCM-produced "present day" $\left(1 \times \mathrm{CO}_{2}\right)$ and. "perturbed" $\left(2 \times \mathrm{CO}_{2}\right)$ climate scenarios.

\section{Methodology}

The modeling of precipitation downscaling from a GCM grid to a regional resolution of a few square kilometers includes two parts. The first part constitutes the classification method of daily circulation patterns that is capable to be implemented for present or future climates (here, precipitation). The second part reflects the precipitation downscaling model linked to the classified circulation patterns. A brief description of method and model operation of the first and second part is presented here.

\subsection{Classification method}

The classification method selected was the fuzzy-rules based approach (Bárdossy et al., 1995) combined with the simulated annealing algorithm (Bárdossy et al., 2002). It consists of three steps: (1) data transformation; (2) definition of the fuzzy rules, and (3) classification of observed data. The classification is carried out using normalized pressure anomalies $g(i, t)$ and daily data with geo-potential ( $i$ stands for the gridpoint and $t$ for the day). The purpose of the classification is to identify unusually wet or dry local conditions from the large scaled pressure distribution. The pressure data used are obtained from the NMC grid-point data set for different windows over Europe with a grid resolution of $5^{\circ} \times 5^{\circ}$.

Each CP is described with a fuzzy rule $k$ represented by a vector $v(k)=\left(v(1)^{(k)} \ldots v(n)^{(k)}\right)$, where $n$ is the number of grid-points for which the air-pressure data are available. The $v(i)^{(k)}$ are the indices of the membership function describing the anomalies corresponding to the selected locations and CP. Five possible types of anomalies described with their membership functions were considered. These are very low, medium low, medium high, very high, and the case that the anomaly at the specific location has no influence on the CP. The membership functions and the calculation of the degree of fulfillment $D O F$ of the rules are explicitly described in Bárdossy et al. (2002).

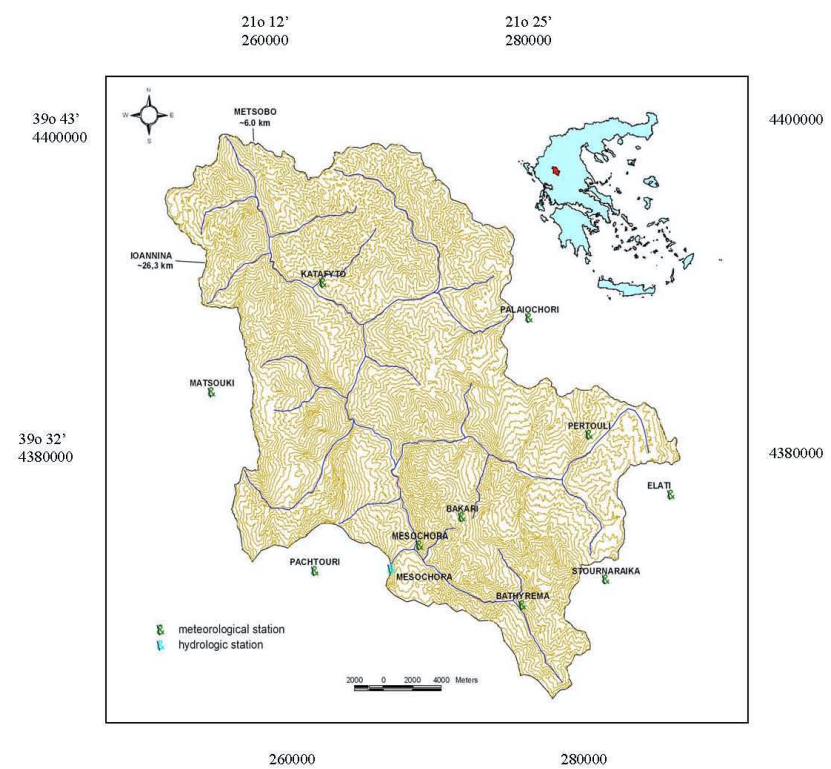

Fig. 1. Elevation contour map and meteorological stations of Mesochora catchment.

In order to find the best possible rules for the description of local precipitation two types of objective functions were used to measure the classification performance. The first deals with the precipitation probability on a given day, and the second with the precipitation amount in order both to define the rainfall variability (very wet and very dry conditions). The algorithms of the optimization functions are fully described in Bárdossy et al. (2002).

\subsection{Precipitation downscaling model}

The main difficulties in mathematical modelling of daily precipitation are its space-time intermittence, the occurrence probability of dry days, the rainfall amounts on wet days, as well as the clustering of wet and dry day occurrence that has great impacts on the CPs persistence. Taking into account these major problems, a modified version of space- time model of Bárdossy and Plate (1992) developed by Stehlik and Bárdossy (2002) was adopted in this work.

In this respect, let $\mathbf{A}=\left\{\alpha_{1}, \ldots, \alpha_{n}\right\}$ be a set of possible atmospheric circulation patterns and $\tilde{\mathrm{A}}_{t}$ be the random variable describing the actual atmospheric circulation taking its values from A. Also, let the daily precipitation amount at time $t$ and point $u$ in the region $U$ be modeled as the random function $Z(t, u)$. The distribution of rainfall amounts at a selected location is skewed. In order to relate it to a simple normally distributed random function $W(t, u)$ (for any locations $u_{1}, \ldots u_{n}$ the vector $\left(W\left(t, u_{1}\right), \ldots, W\left(t, u_{n}\right)\right)$ is a multivariate normal random vector) the following power transformation relationship is introduced.

$Z(t, u)=\left\{\begin{array}{cc}0 & \text { if } W(t, u) \leq 0 \\ W^{\beta}(t, u) & \text { if } W(t, u)>0\end{array}\right.$ 

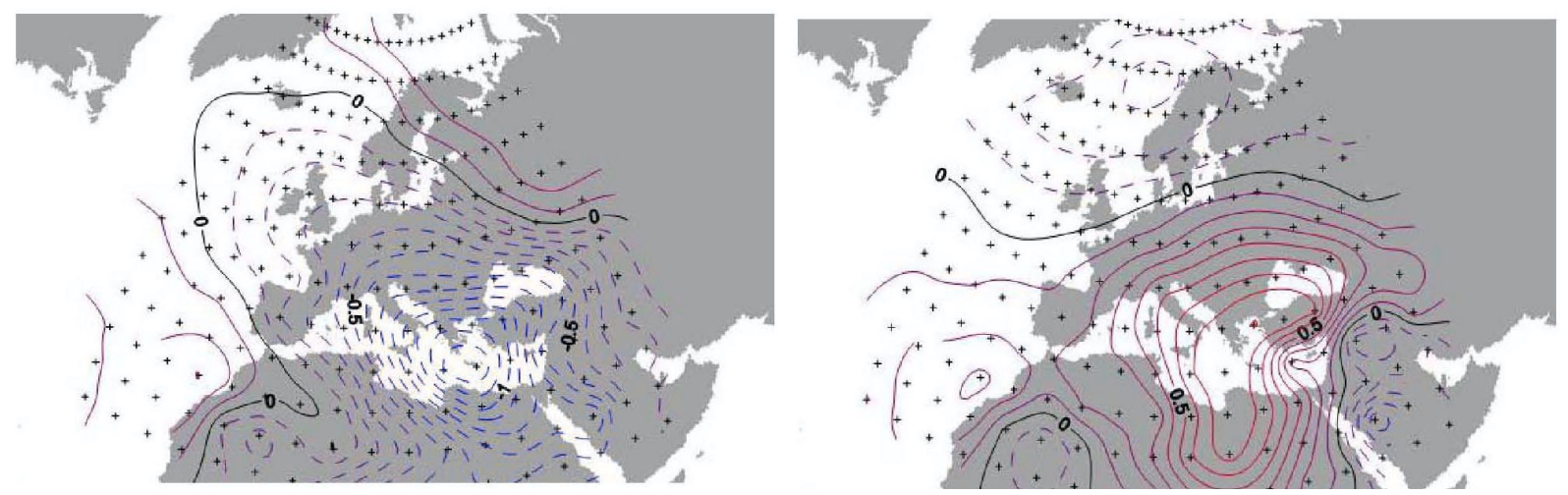

Fig. 2. Mean normalized distributions of $700 \mathrm{hPa}$ geopotential fields of 01 (left) and 09 (right) circulation pattern (CP). (CPs are precipitationoptimized over 1982-1992 with $700 \mathrm{hPa}$ data and 12 stations of Mesochora catchment).

Where, $\beta$ is an appropriate positive exponent. By this way the mixed (discrete-continuous) distribution of $Z(t, u)$ is related to a normal distribution. As the process $Z(t, u)$ depends on the atmospheric circulation pattern, this can be applied to $W(t, u)$. The reason for this transformation is that multivariate processes can be modeled much easier if the process is normally distributed. The intermittence can also be handled by this way, as the negative values of $W$ are declared as dry days and dry locations. The exponent $\beta$ is needed because the distribution of precipitation amounts is generally considered more skewed than the truncated normal distribution.

Equation (1) establishes the link between $W(t)$ and rainfall $Z(t)$ as a multi-site process. The parameters of $W(t)$ depend on the CP and the day of the year $t$. The annual cycle of the parameters is described by using Fourier series.

\section{Study catchment and observed data sets}

The Mesochora catchment drained by Acheloos' river has a great significance for Greece due to partial diversion of the river at the outfall of the catchment to irrigate the arid Thessaly plain. The catchment with an area of about $633 \mathrm{~km}^{2}$ lies in the central mountain region of Greece (Fig. 1) and extends nearly $32 \mathrm{~km}$ from north $\left(39^{\circ} 42^{\prime}\right)$ to south $\left(39^{\circ} 25^{\prime}\right)$ with an average width of about $20 \mathrm{~km}$. The mean elevation is $1390 \mathrm{~m}$, while the elevation from the highest point to the catchment outlet ranges from $2200 \mathrm{~m}$ to $780 \mathrm{~m}$. The climate of the area is dominated by cold and wet winters, as well as by warm and dry summers and the soils have been formed from decay of hard limestones and flysch (clayish, psammitic and mixed).

The precipitation stations are installed within and around the catchment. The most of the stations are cited at the lower half of the catchment over a range of elevations from 780 to $1160 \mathrm{~m}$. Daily values of precipitation were available at 12 stations for the period of 1967-1992.

The precipitation variability at the stations was determined by conditioning on $\mathrm{CP}$ types. It was found that the $700 \mathrm{hPa}$ data in the window $20^{\circ} \mathrm{W}-50^{\circ} \mathrm{E}$ and $20^{\circ}-65^{\circ} \mathrm{N}$ provided the best results, while the optimal number of CPs defined to 12 based on the automated objective optimization procedure for precipitation. As an example, for the Vakari station cited at the middle of the lower half of the catchment, the CP09 is the most frequent (37.20\% average over the year) and also driest contributing to precipitation by $4.0 \mathrm{~mm}$ daily amount and probability $22.50 \%$. At the same station, the CP01 is a typical wet CP (second in wet day amount- $14.0 \mathrm{~mm}$ yearly) with high precipitation probability (65\% yearly) and low occurrence frequency (5.9\% yearly). Figure 2 shows the distributions of the mean (1982-1992) normalized $700 \mathrm{hPa}$ geopotential fields anomalies for the CP01 and CP09.

A spatial correlation function using time series cross correlations was assessed for interpolation of point precipitation data to a regular grid and was subsequently integrated to 9 zones and the entire area. For this purpose external drift kriging (Ahmed and de Marsily, 1987) was used. The zoning distribution of precipitation showed that the precipitation increases slightly with increasing elevation.

\section{Calibration with observed data sets}

In the calibration procedure the observed daily precipitation series for all the available periods were used to estimate the precipitation coupling parameters, which describe the stochastic links between CPs and point measurements. Using these attained parameters the precipitation time series were simulated (generated). It was shown that the stochastic model simulates time series very well in comparison to the measured ones. As an example, for the Vakari station, observed $(4.34 \mathrm{~mm} /$ day $)$ and simulated $(3.95 \mathrm{~mm} /$ day $)$ average daily mean precipitation in a yearly basis agree enough well. Standard deviations of these quantities $3.40 \mathrm{~mm} /$ day (observed) and $2.27 \mathrm{~mm} /$ day (simulated), also show a good agreement. Similar or slightly better values are reflected for the mentioned quantities at the other 9 stations.

Variability and average behavior of precipitation is well described over the annual cycle and in the spatial structure too. As an example, Fig. 3 shows the mean annual cycle of observed and simulated rainfall at Vakari station over the 


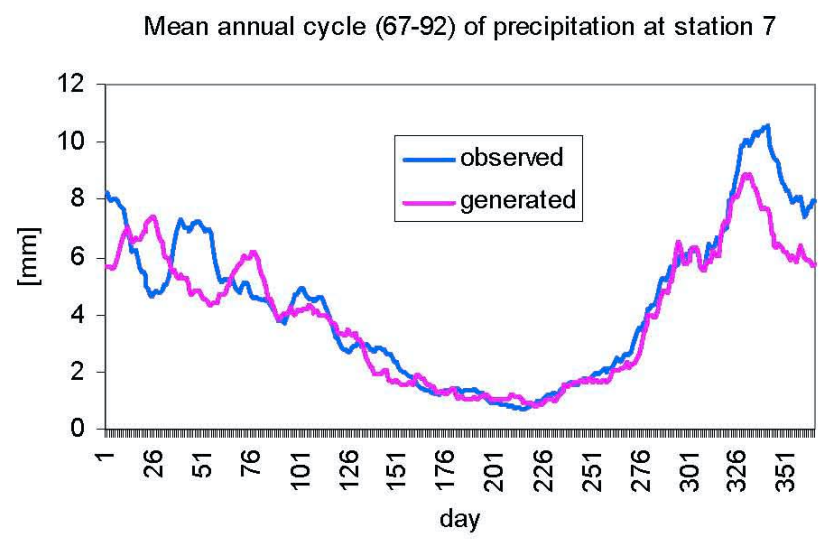

Fig. 3. Mean annual cycle of precipitation at Vakari station. Observed and simulated rainfall for the period 1967-1992.

period 1967-1992. It is very clear from Fig. 3 that the daily rainfall in the dry periods of growing and fall seasons is in good agreement with the measured values. A less good agreement is appeared for annual maxima between modeled and observed profiles. In another example, Fig. 4 shows the normalized precipitation annual cycle (simulated/observed) at Pertouli station over the period 1967-1992. It is obvious from the Fig. 4 that for a single realization of simulated precipitation the values may vary strongly, but in the average (moving average on the Fig. 4) the values are around 1.

\section{Rainfall variability in evolved climate}

Beyond the downscaled precipitation over the Mesochora catchment for the period 1967-1992, downscaling was also carried out for ECHAM4 GCM-generated circulation patterns. The analysis was based on daily values at the aforesaid sector $20^{\circ} \mathrm{W}-50^{\circ} \mathrm{E}$ and $20^{\circ}-65^{\circ} \mathrm{N}$ over the $700 \mathrm{hPa}$ pressure fields for $1 \times \mathrm{CO}_{2}$ and $2 \times \mathrm{CO}_{2}$ scenarios for the corresponding periods $1961-2000$ and $2061-2100$.

Applying the classification method described for the observed data the geo-potential fields at the $700 \mathrm{hPa}$ of both scenarios were classified. With the attained parameters of the stochastic precipitation model for the observed data and forcing the model by the two cases of classified GCM-CPs precipitation, time series were generated responding to climate scenarios.

The daily rainfall variability responding to the evolved climate (1967-1992, 1961-2000, and 2061-2100 periods) for zones and catchment area is given below via a suite of diagnostic statistics. The adopted descriptors give an overview of the character of daily rainfall variability and enable the various changes to be evaluated in the evolving rainfall. The diagnostics describe the daily variability via first order and second order moments, wet and dry-day renewal process probabilities, spell lengths, as well as low-frequency variability via the standard deviation of monthly totals.

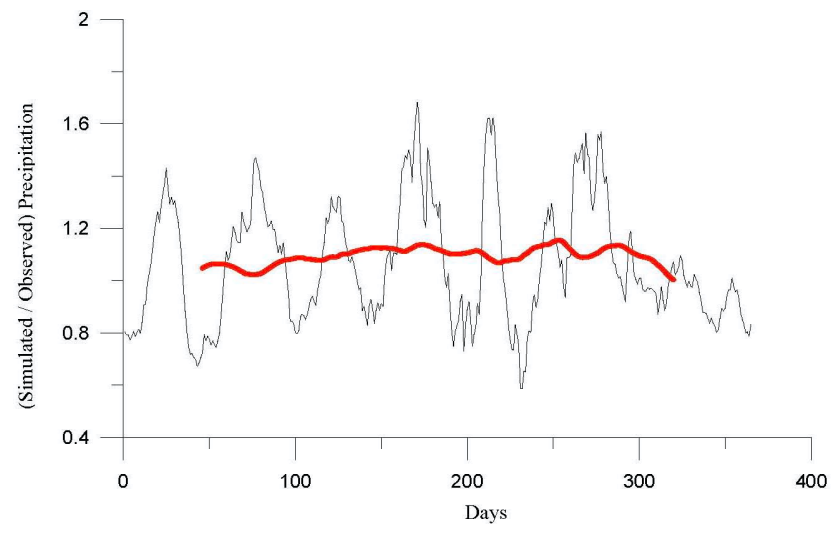

Fig. 4. Mean annual cycle of normalized precipitation (simulated / observed) at Pertouli station for the period 1967-1992.

The statistics' comparison (Table 1) revealed a decrease in mean, median, standard deviation, 95th percentile of wet-day amount (measured in $\mathrm{mm}$ ) and dry-to dry probability $\left(p_{00}\right)$ for the warm scenario $\left(2 \times \mathrm{CO}_{2}\right.$ case $)$ progressively from the lower (zone 1) to the upper zone (zone 9) in relation to the observed case. The decrease in the above statistics is greater over the catchment area.

The probabilities in wet-to-wet day $\left(p_{11}\right)$ and wet-to-dry day $\left(p_{10}\right)$ showed an unstable and no significant increase or decrease among the 9 zones. In contrast, the probability in dry-to-wet day $\left(p_{01}\right)$ and the unconditioned probability on a wet day $\left(\pi_{w}\right)$ reflected a stable increase among the 9 zones rising to $82 \%$ and $22 \%$ respectively for the catchment area.

Concerning the dry spell statistics, the mean dry-spell length ( $L_{d}$ in days), the standard deviation of $\mathrm{L}_{d}$ and the 90th percentile of $L_{d}$ decreased for the most of the zones marking a general decrease by $50 \%$ over the catchment area. The wet spell statistics, i.e. the mean wet-spell length ( $L_{w}$, in days), the standard deviation of $L_{w}$, and the 90th percentile of $L_{w}$ were reduced slightly or remained constant for the most of the zones reflecting so to the entire area an increase by $4 \%$ in $L_{w}$ and $14 \%$ in 90th percentile of $L_{w}$.

The low-frequency diagnostic i.e., the standard deviation of monthly rainfall total (measured in $\mathrm{mm}$ ) decreased for the 4 lower zones and increased slightly to the other zones, providing so a decrease of $1 \%$ to the catchment area.

\section{Summary and conclusions}

A multivariate stochastic downscaling model (Stehlik and Bárdossy, 2002) coupled with atmospheric circulation was employed to generate daily precipitation series for an evolving climate. The fuzzy rule-based automated objective classification method of Bárdossy et al. (2002) was used to classify both observed CPs and GCM-produced CPs for $1 \times \mathrm{CO}_{2}$ and $2 \times \mathrm{CO}_{2}$ climate scenarios. The so resulted daily precipitation series was used for identifying differences between present and future climates. 
Table 1. Diagnostic statistics' results for observed, $1 \mathrm{CO}_{2}$ and $2 \mathrm{CO}_{2}$ downscaled daily precipitation over zones and catchment area.

\begin{tabular}{|c|c|c|c|c|c|c|c|c|c|c|c|c|c|c|c|}
\hline \multirow{2}{*}{ Diagnostics } & \multicolumn{3}{|c|}{ Zone 1} & \multicolumn{3}{|c|}{ Zone 2} & \multicolumn{3}{|c|}{ Zone 3} & \multicolumn{3}{|c|}{ Zone 4} & \multicolumn{3}{|c|}{ Zone 5} \\
\hline & Obs. & $1 \mathrm{CO}_{2}$ & $2 \mathrm{CO}_{2}$ & Obs. & $1 \mathrm{CO}_{2}$ & $2 \mathrm{CO}_{2}$ & Obs. & $1 \mathrm{CO}_{2}$ & $2 \mathrm{CO}_{2}$ & Obs. & $1 \mathrm{CO}_{2}$ & $2 \mathrm{CO}_{2}$ & Obs. & $1 \mathrm{CO}_{2}$ & $2 \mathrm{CO}_{2}$ \\
\hline Mean wet-day amount: & 9.25 & 9.63 & 8.68 & 7.56 & 7.53 & 6.82 & 7.34 & 7.17 & 6.53 & 7.75 & 7.50 & 6.98 & 8.54 & 8.55 & 8.08 \\
\hline Standard deviation of wet-day amount: & 14.05 & 14.31 & 12.98 & 11.41 & 11.51 & 10.36 & 10.77 & 10.77 & 9.78 & 10.94 & 10.98 & 10.17 & 11.97 & 12.05 & 11.36 \\
\hline Median wet-day amount: & 3.90 & 4.10 & 3.80 & 3.10 & 3.10 & 2.90 & 3.00 & 3.00 & 2.80 & 3.30 & 3.20 & 3.10 & 4.00 & 3.90 & 3.80 \\
\hline 95th percentile of wet-day amount: & 36.29 & 38.20 & 33.72 & 29.60 & 29.90 & 26.80 & 28.91 & 27.90 & 25.80 & 30.22 & 29.30 & 26.82 & 32.50 & 32.70 & 30.50 \\
\hline$P_{00}:$ & 0.76 & 0.62 & 0.59 & 0.74 & 0.57 & 0.53 & 0.74 & 0.58 & 0.53 & 0.73 & 0.61 & 0.57 & 0.72 & 0.64 & 0.62 \\
\hline$P_{11}:$ & 0.75 & 0.71 & 0.73 & 0.79 & 0.77 & 0.79 & 0.79 & 0.77 & 0.78 & 0.74 & 0.73 & 0.74 & 0.68 & 0.67 & 0.69 \\
\hline$P_{01}:$ & 0.24 & 0.38 & 0.41 & 0.26 & 0.43 & 0.47 & 0.26 & 0.42 & 0.47 & 0.27 & 0.39 & 0.43 & 0.28 & 0.36 & 0.38 \\
\hline$P_{10}:$ & 0.25 & 0.29 & 0.27 & 0.21 & 0.23 & 0.21 & 0.21 & 0.23 & 0.22 & 0.26 & 0.27 & 0.26 & 0.32 & 0.33 & 0.31 \\
\hline$\pi_{w}$ & 0.49 & 0.57 & 0.60 & 0.55 & 0.65 & 0.69 & 0.55 & 0.65 & 0.68 & 0.51 & 0.59 & 0.62 & 0.47 & 0.52 & 0.55 \\
\hline$L_{d}:$ & 4.14 & 2.65 & 2.44 & 3.78 & 2.33 & 2.13 & 3.78 & 2.36 & 2.12 & 3.65 & 2.55 & 2.34 & 3.51 & 2.81 & 2.62 \\
\hline$L_{w}:$ & 4.02 & 3.48 & 3.67 & 4.79 & 4.36 & 4.78 & 4.71 & 4.3 & 4.63 & 3.85 & 3.67 & 3.86 & 3.15 & 3.06 & 3.19 \\
\hline Standard deviation of $L_{d}$ : & 4.6 & 2.32 & 2.07 & 3.88 & 1.92 & 1.69 & 3.87 & 1.96 & 1.69 & 3.87 & 2.2 & 1.91 & 3.82 & 2.57 & 2.22 \\
\hline Standard deviation of $L_{w}$ : & 4.16 & 3.97 & 3.94 & 5.23 & 4.9 & 5.45 & 5.27 & 4.75 & 5.25 & 3.69 & 3.88 & 4.07 & 2.85 & 2.99 & 3.08 \\
\hline 90th percentile of $L_{d}$ : & 9 & 6 & 5 & 8 & 5 & 4 & 8 & 5 & 4 & 8 & 5 & 5 & 8 & 6 & 5.2 \\
\hline 90th percentile of $L_{w}$ : & 9 & 8 & 8 & 11 & 10 & 11 & 11 & 10 & 11 & 8 & 8 & 9 & 6 & 7 & 7 \\
\hline Standard deviation of monthly precipitation total: & 124.84 & 130.61 & 121.72 & 106.03 & 111.4 & 102.52 & 96.38 & 102.5 & 94.26 & 89.04 & 95.87 & 88.52 & 88.51 & 95.6 & 88.74 \\
\hline
\end{tabular}

Table 1. Continued.

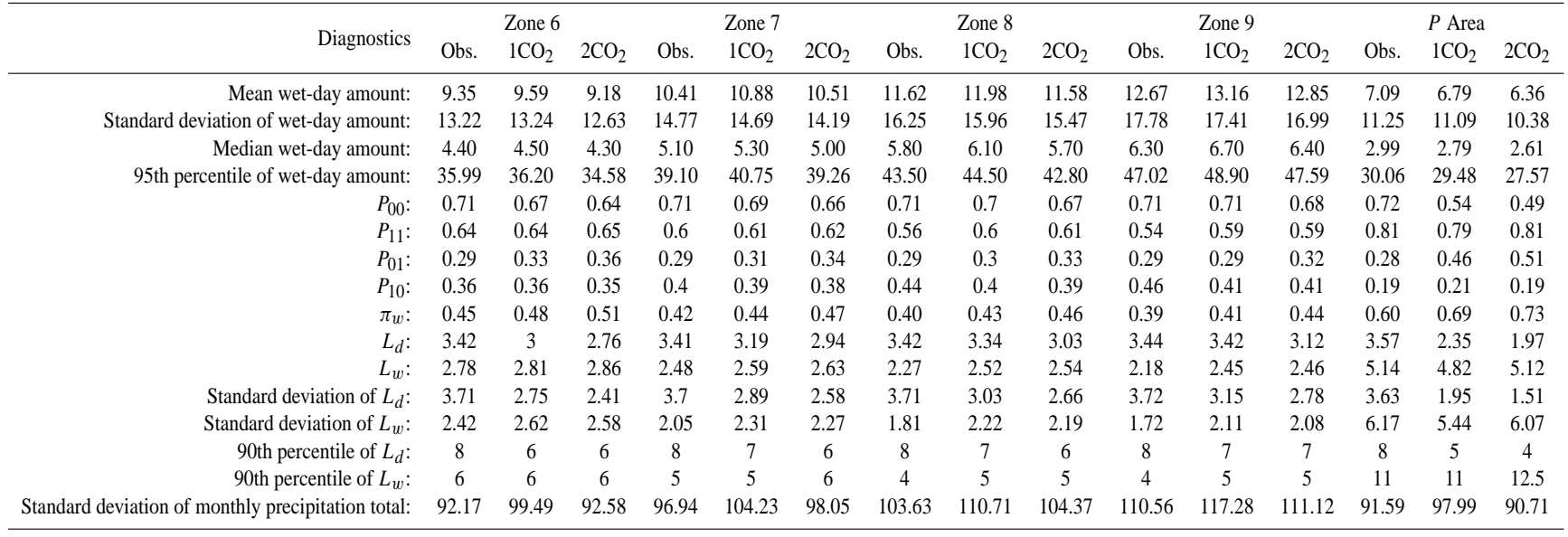

The comparison of daily rainfall variability for observed, present $\left(1 \times \mathrm{CO}_{2}\right)$ and future $\left(2 \times \mathrm{CO}_{2}\right)$ climate over the 9 zones and the entire area of the Mesochora catchment in Central Greece by using a suite of diagnostic statistics revealed that: (a) there is a general decrease in the values of the first order and the second order moments as well as in the values of the dry-to-dry day renewal process probabilities over zones and entire area, (b) the wet-to-wet/dry day renewal process probabilities remain substantially unchanged for zones and total area, (c) the values of dry spell statistics decrease, (d) the values of wet spell statistics do not change significantly over zones and total area, and (e) the value in the standard deviation of monthly rainfall total remains almost unchanged for the catchment area.

The (a)-(e) above findings suggest a possible increase in daily rainfall occurrence (arrival process) with a decreasing rainfall amount and a sequence of less consecutive dry days that would occur under $\mathrm{CO}_{2}$ doubling for any given catchment with a similar nature in hydrological and meteorolog- ical characteristics to the examined one. Diversity could be probably noticed by applying the followed methodology to other GCM outputs.

Acknowledgements. The authors would like to thank the reviewer, S. Lykoudis for his constructive comments.

Edited by: V. Kotroni and K. Lagouvardos

Reviewed by: S. Lykoudis

\section{References}

Ahmed, S. and de Marsily, G.: Comparison of geo-statistical methods for estimating transmissivity using data on transmissivity and specific capacity, Wat. Resour. Res., 23, 1717-1737, 1987.

BAHC Core Project Office: Biospheric aspects of the hydrological cycle, Rep. 27, Institut fur Meteorologie, Berlin, 1993.

Bárdossy, A., Stehlík, J., Caspary, H. J.: Automated optimized fuzzy rule based circulation pattern classification for precipitation and temperature downscaling, Clim. Res., 22, 11-22, 2002. 
Bárdossy, A., Duckstein, L., and Bogárdi, I.: Fuzzy rule-based classification of atmospheric circulation patterns, Int. J. Climatol., 15, 1087-1097, 1995.

Bárdossy, A. and Plate, E. J.: Space-time model of daily rainfall using atmospheric circulation patterns, Wat. Resour. Res., 28(5), 1247-1259, 1992.

Giorgi, F. and Mearns, L. O.: Approaches to the simulation of regional climate change - A review, Rev. Geophys., 29, 191-216, 1991.

Hay, L. E., McCabe, G. J., Wolock, D. M., and Ayers, M. A.: Simulation of precipitation by weather type analysis, Water Resour. Res., 27, 493-501, 1991.

Heyen, H. , Zorita, E., and von Storch, H.: Statistical downscaling of monthly mean N. Atlantic air pressure to sea level anomalies in the Baltic Sea, Tellus Ser. A., 48, 312-323, 1996.

Hughes, J. P. and Guttorp, P.: A class of stochastic model for relating synoptic atmospheric patterns to regional hydrologic phenomena, Water Resour. Res., 30, 1535-1546, 1994.

Laevesley, G. H.: Modeling the effects of climate change on water resources - A review, Clim. Change, 28, 159-177, 1994.
Leroux, M.: Atmospheric Circulation, Perturbation, Climatic Evolution in Dynamic Analysis of Weather and Climate, WileyPraxis Series in Atmospheric Physics, 1998.

Maochang, C. H., von Storch, H., and Zorita, E.: Coastal sea level and large-scale climate state. A downscaling exercise for the Japanese Islands, Tellus Ser. A., 47, 132-144, 1995.

Stehlik, J. and Bárdossy, A.: Multivariate stochastic downscaling model for generating daily precipitation series based on atmospheric circulation, J. Hydrol., 256, 120-141, 2002.

Wilby, R. L. and Wigley, T. M. L.: Downscaling general circulation model output: a review of methods and limitations, Progress Phys. Geogr., 21, 530-548, 1997.

Wilby, R. L., Wigley, M. L., Conway, D., Jones, P. D., Hewitson, B. C., Main, J., and Wilks, D. S.: Statistical downscaling of general circulation model output: a comparison of methods, Water Resour. Res., 34 (11), 2995-3008, 1998.

Wilby, R. L., Hay, L. E., and Leavesley, G. H.: A comparison of downscaled and raw GCM output: implications for climate change scenarios in the San Juan River basin, Colorado, J. Hydrol., 225, 67-91, 1999. 